\title{
NEOTECTÔNICA NO PLANALTO DE CAMPOS DO JORDÃO, SP
}

\section{SILVIO TAKASHI HIRUMA ${ }^{1}$, CLAUDIO RICCOMINI ${ }^{2} \&$ MAY CHRISTINE MODENESI-GAUTTIERI $^{3}$}

\begin{abstract}
RESUMO Estudos geomorfológicos e estruturais efetuados no frontão sudeste do Planalto de Campos do Jordão, SP, tiveram por finalidade estabelecer o quadro neotectônico da região e verificar a continuidade dos regimes de esforços identificados em áreas vizinhas. A atividade tectônica durante o Quaternário é expressa no relevo por fenômenos de captura de drenagem, rios em gancho, vales assimétricos, escarpas retilíneas, facetas triangulares e trapezoidais, anfiteatros suspensos, shutter ridges e divisores pouco nítidos. A análise morfoestrutural, incluindo a caracterização de estruturas rúpteis e depósitos quaternários, permitiu reconhecer um padrão de superposição de regimes de esforços neotectônicos, semelhante ao observado em áreas vizinhas, como o Vale do Rio Paraíba do Sul e a região do Alto Estrutural de Queluz Um regime inicial compressivo NW - SE, compatível com um binário transcorrente dextral, de direção E - W (Neopleistoceno a Holoceno), teria sido seguido por outro distensivo E - W a NW-SE, evidenciado por falhas normais de direção NE - SW, que afetam depósitos holocênicos. Esta sucessão seria fechada por um regime de esforços compressivo de direção E-W a NW-SE - compatível com o regime atual de esforços horizontais máximos obtido a partir de dados geofísicos - definido por juntas neotectônicas subverticais que afetam colúvios e solos orgânicos.
\end{abstract}

Palavras - chaves: neotectônica, morfotectônica, Quaternário, Rifi Continental do Sudeste do Brasil, Planalto de Campos do Jordão.

\begin{abstract}
NEOTECTONICS IN THE CAMPOS DO JORDÃO PLATEAU, SP Geomorphologic and structural studies focusing on the southeastern border of the Campos do Jordão Plateau have elucidated the neotectonic evolution of this region and revealed the continuity of stress regimes identified in the surrounding areas. Quaternary tectonic activity is evidenced in the relief by river capture phenomena, countercurrent confluences, asymmetric valleys, straight scarps, triangular and trapezoidal facets, hanging amphitheaters, shutter ridges and indistinct drainage divides. Morphostructural analysis, including characterization of brittle structures and Quaternary deposits, identified superposed neotectonic regimes, very similar to those observed in the surrounding areas, e.g. the Paraíba do Sul River Valley and the Queluz Structural High. An initial NW-SE compression, compatible with an E-W right-lateral strike-slip shear couple (Late Pleistocene/Holocene), was followed by E-W to NW-SE extension, responsible for normal faults in Holocene deposits. This regime was succeeded by E-W to NW-SE compression - compatible with the present-day horizontal maximum stress obtained from geophysical data - that generated neotectonic joints in colluvium and organic-rich soils.
\end{abstract}

Keywords: neotectonics, morphotectonics, Quaternary, Continental Rift of Southeastern Brazil, Campos do Jordão Plateau.

\begin{abstract}
INTRODUÇÃo Registros de atividade neotectônica vêm sendo descritos em diversos setores do Brasil de sudeste, como no sul de Minas Gerais (Saadi 1991, Santos et al. 1999), Vale do Paraíba (Riccomini 1989, Salvador \& Riccomini 1995, Mancini 1995, Mello et al. 1995), Serra da Bocaina (Gontijo 1999), litoral do Estado do Rio de Janeiro (Silva \& Ferrari 1997), entre outros. A presença desses registros, inclusive durante o Holoceno, mostra a importância de se conhecer o quadro neotectônico para avaliar a estabilidade geológica de áreas e riscos sísmicos decorrentes, essencial para a implantação de obras de engenharia de grande porte, tais como centrais nucleares, gasodutos e reservatórios de usinas hidrelétricas (vide Hasui \& Mioto 1992). O conhecimento da orientação e magnitude do campo de esforços contemporâneo permite avaliar a permeabilidade de fraturas e, deste modo, inferir o fluxo de fluidos em subsuperfície, sendo igualmente importante para a geologia de petróleo e a hidrogeologia (Stewart \& Hancock 1994). Estudos vêm sendo realizados para definir o papel da tectônica recente na deflagração de processos geomorfológicos, tais como movimentos de massa e crosão (Hasui et al. 1995).
\end{abstract}

Evidências morfológicas descritas na literatura científica já indicavam a presença de um tectonismo recente no Planalto de Campos do Jordão. No Guia de Excursão da I Reunião Panamericana de Consulta sobre Geografia, Ruellan (1952) apresentava como hipótese a subdivisão do planalto em pequenos blocos falhados e basculados, separados por depressões de ângulo de falha. Modenesi (1980, 1983, 1988a, 1988b) identificou anomalias de drenagem ao longo da Zona de Cisalhamento de Jundiuvira na porção colinosa e pouco dissecada do frontão sudeste do planalto. Na área do Morro da Pedra do Fogo c do Vale do Ribeirão do Fojo, verificou que os anfiteatros mais recentes inserem-se em facetas trapezoidais ou triangulares esculpidas nos esporões laterais de anfiteatros da geração imediatamente anterior: Saadi (1991) caracterizou o compartimento dos blocos da Serra da Mantiqueira pelo agrupamento de serras alongadas $\mathrm{cm}$ direção princi- pal SSW-NNE, que apresentam invariavelmente uma dissimetria marcada, com a face exposta a sudeste ou sudoeste sempre mais íngreme e desnuda. Os basculamentos dos blocos tectônicos para noroeste ou nordeste constituiriam a tônica principal dessa morfologia.

A sobrelevação final da Mantiqueira teria ocorrido durante o Quaternário, paralelamente ao incremento dos deslocamentos verticais ao longo dos rifts, ao entulhamento das bacias, acentuação do basculamento dos testemunhos da Superfície Japi c dissecação erosiva importante, tanto das vertentes meridional da Serra do Mar e setentrional da Mantiqueira, quanto da borda sudeste da Bacia do Paraná (Almeida 1976). Esta idéia seria corroborada pela presença de vales quaternários suspensos e deformações tectônicas em terraços fluviais na Serra da Mantiqueira mineira (Saadi 1993). No Planalto de Campos do Jordão, lateritas aluminoferruginosas encontradas acima de $1800 \mathrm{~m}$ e restos de latossolos retrabalhados nas vertentes do nível topográfico de $1.800-1.820 \mathrm{~m}$ representariam prováveis resquícios de um manto ferralítico, formado sob condições e processos vigentes antes da acentuação do soerguimento do planalto (Modenesi 1984). Trabalhos mais recentes sobre traços de físsão em apatitas indicam uma taxa de soerguimento significativa da margem continental do sudeste brasileiro desde o Cretáceo (Gallagher et al. 1995, Amaral et al. 1997, Hackspacher et al. 1999).

$O$ presente trabalho visa definir e caracterizar o quadro neotectônico do Planalto de Campos do Jordão e verificar a continuidade - orientação e idade - dos regimes de esforços observados em áreas vizinhas, como o Vale do Rio Paraíba do Sul (Riccomini 1989) e a região do Alto Estrutural de Queluz (Salvador \& Riccomini 1995). Cabe ressaltar que o Planalto de Campos do Jordão faz parte da Zona Sismogênica de Cunha (Mioto 1993), que apresenta atividade sísmica significativa, com alguns sismos de magnitude em torno de $4 \mathrm{M}_{\mathrm{b}}$, além daqueles induzidos pelas barragens-reservatório de ParaibunaParaitinga.

1 - Instituto Geológico - Secretaria do Meio Ambiente/São Paulo - Av. Miguel Stéfano, 3900 CEP: 04301-903, São Paulo, SP, Brasil - E-mail: hiruma@igeologico.sp.gov.br

2 - Instituto de Geociências da Universidade de São Paulo (IG-USP) e Bolsista de Produtividade em Pesquisa do Conselho Nacional de Desenvolvimento Científico e Tecnológico (CNPq) - Caixa Postal 11.348, CEP 05422-970, São Paulo, SP, Brasil - E-mail: riccomin@usp.br

3 - Instituto Geológico - Secretaria do Meio Ambiente/São Paulo - Av. Miguel Stéfano, 3900 CEP: 04301-903, São Paulo, SP, Brasil - E-mail: modenesi@igeologico.sp.gov.br 

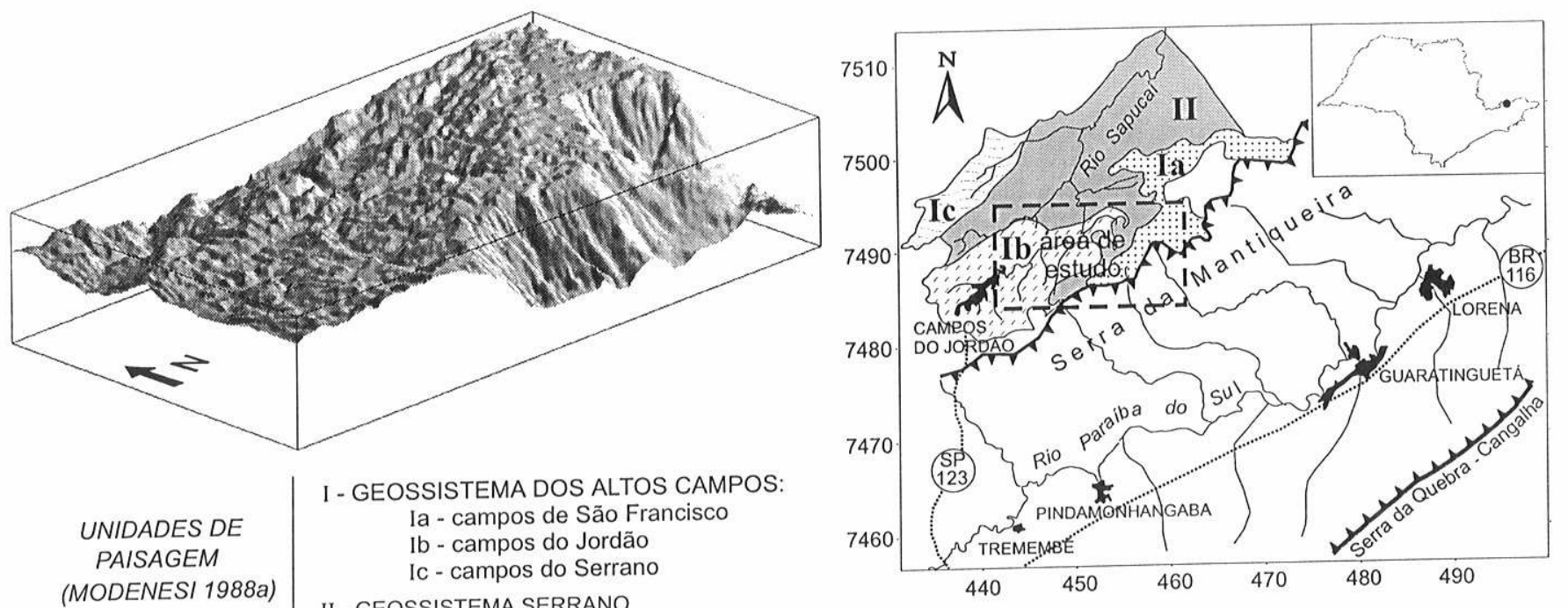

UNIDADES DE

PAISAGEM

(MODENESI 1988a)
II - GEOSSISTEMA SERRANO

I - GEOSSISTEMA DOS ALTOS CAMPO
la - campos de São Francisco

b - campos do Jordão

Ic - campos do Serrano

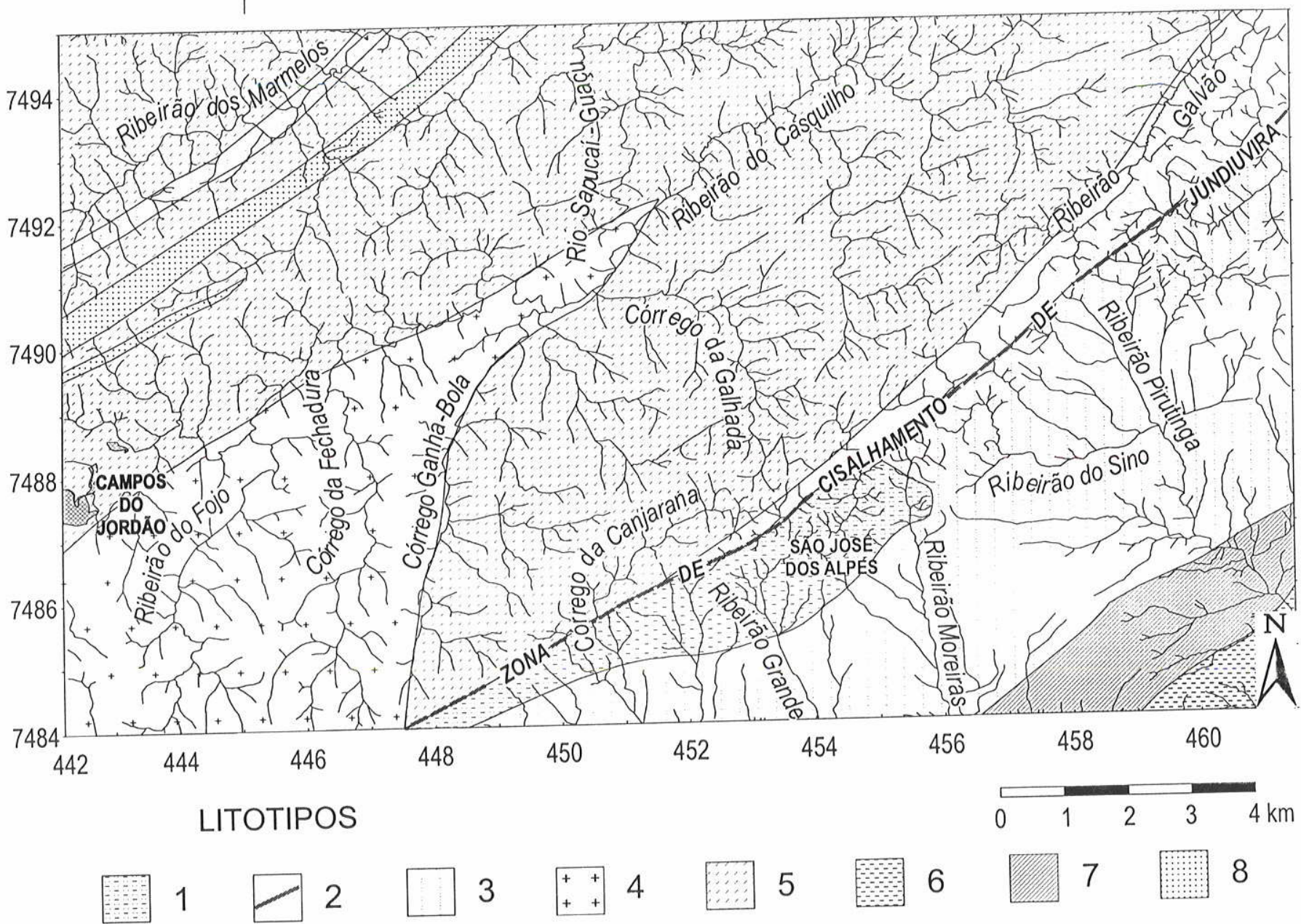

Figura 1: Principais litotipos, localização da área de estudo no contexto das unidades de paisagem do Planalto de Campos do Jordão e modelo digital de

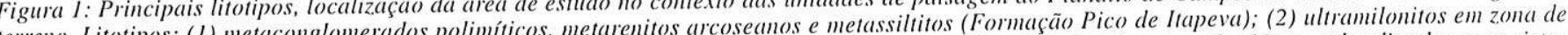
terreno. Litotipos: (1) metaconglomerados poliminicos, metarenitos arcoseanos e metassilhitos (Formaşäs Pies de lipe cisalhamento; (3) predominância de milonito gnaisses; (4) predominância de biotita granitos (3a e 3b), localmente miloniticos, subordinadamente xistos feldspatizados e biotita gnaisses bandados; (5) predominância de biotita gnaisses bandados; (6) migmatitos estromáticos e biotra gnaisses bángico simplipredominância de biotita gnaisses porfiroblásticos e biotita xistos; (8) predominância de muscovita quartzitos, por vezes miloníticos. Mapa geologico simplificado de Hiruma (1999), compilado de Hasui et al. (1978), Cavalcante et al. (1979) e Morais (1998). Sistema de coordenadas: UTM (Universal Transversa de Mercator).

A área estudada abrange o frontão sudeste do Planalto de Campos do Jordão e parte da escarpa da Serra da Mantiqueira (Fig. 1), ambos em terras paulistas, e corresponde à área onde as feições morfológicas indicativas de tectonismo recente são mais nítidas e as evidências estruturais e tectônicas podem ser buscadas com maior probabilidade de êxito.
PLANALTO DE CAMPOS DO JORDÃO: ASPECTOS GEOLóGICOS E GEOMORFOLóGICOS O Planalto de Campos do Jordão está inserido na Região de Dobramentos Sudeste (Almeida et al. 1976) que inclui rochas geradas no Ciclo Brasiliano e, em parte, resultantes do retrabalhamento de rochas mais antigas. Gnaisses, granitos, biotita xistos, quartzitos, migmatitos e metassedimentos da For- 
mação Pico de Itapeva representam os principais litotipos da área de estudo (Hasui et al. 1978, Cavalcante et al. 1979, Riccomini 1993, Morais 1998, Hiruma 1999) (Fig. 1).

A partir do Neojurássico, a região foi submetida a fenômenos relacionados com a Reativação Wealdeniana (Almeida 1967), também conhecida como evento Sul-Atlantiano (Schobbenhaus et al. 1984), que culminaram com a ruptura do Gondwana Ocidental e a abertura do Oceano Atlântico Sul, no Eocretáceo. Movimentos verticais opostos descendentes na Bacia de Santos e ascendentes na região continental vizinha (Almeida 1967, Asmus \& Ferrari 1978) - teriam tido importantes efeitos na porção continental e na porção offshore, onde são registrados rejeitos verticais da ordem de quilômetros. Durante o Paleógeno (Eoceno-Oligoceno) a reativação normal de antigas zonas de cisalhamento originou uma importante feição tectônica: o Rift Continental do Sudeste do Brasil - RCSB (Riccomini 1989), anteriormente denominado de Sistema de Rifts da Serra do Mar por Almeida (1976). Na porção leste do Estado de São Paulo, a evolução dessa feição tectônica deu origem à configuração atual do relevo, representado pelas Serras do Mar e Mantiqueira, como feições soerguidas, e a Bacia de Taubaté, como feição rebaixada.

A evolução do Rift Continental do Sudeste do Brasil, segundo o modelo tectônico proposto por Riccomini (1989), compreendeu 4 fases tectônicas: a) distensivo NNW-SSE inicial - Paleógeno; b) transcorrência sinistral - Neógeno (Mioceno?); c) transcorrência dextral - Neopleistoceno; d) distensivo NW(WNW) - SE(ESE) final Holoceno. Uma última fase compressiva E-W, identificada no Alto Estrutural de Queluz (Salvador \& Riccomini 1995), é compatível com o regime atual de esforços horizontais máximos, obtidos a partir de dados geofísicos (Assumpção 1992). Esse mesmo modelo foi identificado na região do Médio Vale do Rio Doce, MG (Mello 1997). Saadi (1991) propõe um modelo um pouco diferente para a evolução tectônica cenozóica da região de Minas Gerais. Estabelece dois eventos tectônicos principais: o primeiro no Eoceno-Oligoceno, responsável pela geração do sistema de rifts e o segundo, entre o final do Mioceno e o Plioceno, de caráter compressivo, com esforços horizontais de direção média NW-SE. Segundo o mesmo autor, as atividades cenozóicas na região do RCSB e em bacias vizinhas estariam associadas à zona de fraqueza denominada Descontinuidade Crustal do Paraíba do Sul (DCPS). Padrões de regimes de esforços similares foram observados na Serra da Bocaina (Gontijo 1999).

O Planalto de Campos do Jordão, situado na porção sudoeste do bloco principal da Serra da Mantiqueira, pertence à Província Geomorfológica do Planalto Atlântico (Almeida 1964). Alçado a mais de $2.000 \mathrm{~m}$ de altitude, compõe, juntamente com o Planalto da Bocaina, os altos blocos de planaltos cristalinos (Ab'Sáber 1956). Nas porções mais elevadas desses planaltos, De Martonne (1943) reconheceu a "Superfície dos Campos" de provável idade paleogênica (Ab'Sáber \& Bernardes 1958), mais antiga que a "superfície das cristas médias". Freitas (1951) e Almeida (1964) consideram que se trata da mesma superfície, deformada e erguida em vários níveis.

Duas grandes falhas transcorrentes reativadas de direção NE e de idade pré-cambriana a eopaleozóica delimitam o planalto (Modenesi 1988a): a Falha de Jundiuvira (Hasui et al. 1978), próxima da escarpa da Mantiqueira, e a Falha do Paiol Grande (Hasui et al. 1978) ou de São Bento do Sapucaí (Cavalcante et al. 1979), no seu flanco norte. A drenagem do planalto, tributária do Rio Grande na Alta Bacia do Rio Sapucaí, apresenta-se perfeitamente hierarquizada (Almeida 1964). Os principais coletores do planalto, como o Sapucaí-Mirim, apresentam traçados quase normais às estruturas regionais, fluindo de sul para norte, enquanto a drenagem de menor hierarquia é essencialmente subseqüente, concordante com os principais lineamentos estruturais de direção ENE.

O Planalto de Campos do Jordão apresenta-se como cimeira subnivelada, degradada e desdobrada em níveis erosivos embutidos (Modenesi 1988a). Sua evolução quaternária, em condições de clima de altitude, originou um sistema de paisagem tropical, os altos campos (Modenesi 1980, 1983, 1988a, 1988b), caracterizado pela distribuição da vegetação em típico mosaico de mata e campo. Os campos recobrem topos de interflúvio e setor convexo das vertentes, a mata ocupa o setor retilíneo inferior das vertentes convexas, as vertentes retilíneas e os anfiteatros de erosão. Duas unidades de paisagem, fisionomicamente heterogêneas, foram reconhecidas no Planalto de Campos do Jordão: o geossistema dos altos campos e o geossistema serrano (Fig. 1). Cada um desses geossistemas apresenta variações associadas principalmente a diferenças do substrato e ao grau de dissecação do relevo. No geossistema dos altos campos diferenciam-se três unidades: os campos do Jordão, do Serrano e de São Francisco.

A análise do modelado e da estrutura superficial da paisagem dos altos campos do planalto levou ao reconhecimento de uma alternância de fases de maior e menor atividade erosiva nas vertentes durante o Quaternário (Modenesi 1980, 1983). Regolitos profundos préquaternários teriam sido mobilizados durante o Pleistoceno por uma seqüência de movimentos de massa formando pelo menos 3 gerações de anfiteatros de erosão e seus depósitos correlativos. A diminuição da atividade morfogenética e mudança nos processos de vertente é documentada pelas sequiências coluviais com paleossolos intercalados, que ocorrem principalmente no terço inferior das "lombas", e pelos sedimentos das depressões da base dos anfiteatros. A seção mais completa destes depósitos - descrita na Vila Nova Suíça, Campos do Jordão (Modenesi 1988a) - apresenta uma seqüência de três colúvios $\left(C_{1}, C_{I I}\right.$ $\mathrm{e}_{\mathrm{III}}$ ) com paleossolos intercalados.

\section{CONCEITOS E MÉTODOS O termo neotectônica foi introduzi-} do por Obruchev (1948) para designar movimentos tectônicos recentes, ocorridos no fim do Terciário e início do Quaternário, que tiveram papel decisivo na formação da topografia contemporânea. Desde então, este termo sofreu modificações sucessivas, para um melhor ajustamento aos mecanismos e períodos de manifestação dos eventos neotectônicos (Angelier 1976, Vita-Finzi 1986, Mörner 1978 apud Mörner 1989, Pavlides 1989). Mörner (1993) ressalta que a maioria das definições não estabelece o período a partir do qual os eventos neotectônicos ter-se-iam iniciado globalmente. Entretanto, considera que os últimos $3 \mathrm{Ma}$ teriam sido caracterizados por intensa atividade tectônica, podendo ser identificados como um "período neotectônico".

O termo neotectônica é aqui empregado segundo a definição da Comissão de Neotectônica da International Union for Quaternary Research - INQUA (Mörner 1978 apud Mörner 1989) e refere-se a quaisquer movimentos da Terra ou deformação do nível de referência geodésico, seus mecanismos, sua origem geológica (quão antiga possa ser), suas implicações para vários propósitos práticos e suas extrapolações futuras. O termo morfotectônico é aqui usado para designar formas ou paisagens originadas sob controle tectônico ativo, conforme a concepção de Saadi (1991).

Os métodos adotados no estudo do Planalto de Campos do Jordão combinam análises estruturais e morfotectônicas. As técnicas utilizadas no estudo morfotectônico incluem trabalhos de campo, interpretação de fotos aéreas e imagens de satélite e leitura detalhada de cartas topográficas, em diferentes escalas (Doornkamp 1986, Panizza \& Castaldini 1987). A identificação de feições neotectônicas baseia-se no reconhecimento da idade das camadas mais recentes afetadas por estes movimentos e das formas criadas (escarpas abruptas e não dissecadas, facetas bem preservadas, base linear de escarpas, entre outras).

A interpretação de imagens de satélite (escalas 1:100.000 e $1: 250.000$ ) e de radar (escala 1:250.000) e cartas de sombreamento de relevo, com diferentes azimutes e elevações solares, permitiu a extração de fotolineamentos (Liu 1987, Riccomini \& Crósta 1988). Fotointerpretação na escala 1:25.000 permitiu o reconhecimento de áreas de ocorrência de depósitos quaternários (alúvios, colúvios etc) e a identificação de feições morfológicas indicativas de tectonismo recente, tais como escarpas retilíneas (Wallace 1978, Stewart \& Hancock 1990), facetas triangulares e trapezoidais (Wallace 1978), capturas de drenagem (Biancotti 1979), shutter ridges (Cotton 1948) e formação de lagos (Cotton 1948).

A partir da análise de falhas rúpteis e estrias, empregando-se métodos gráficos (Angelier \& Mechler 1977, Angelier 1994), foram estabelecidos os campos de esforços; o sentido de movimento das falhas foi identificado por indicadores cinemáticos (Petit 1987, Angelier 1994, Doblas et al. 1997). Para a análise de falhas relacionadas à tectônica transcorrente em níveis crustais rasos adotou-se o esquema de Zalán (1986) para cisalhamento simples. A caracterização dos sistemas de 
juntas seguiu a classificação de Hancock \& Engelder (1989), que vem sendo adotada em trabalhos efetuados no Brasil (Salvador \& Riccomini 1995, Riccomini 1997).

A caracterização dos depósitos quaternários afetados por estruturas rúpteis baseou-se nos trabalhos de Modenesi (1984, 1988a, 1988b). A datação $\mathrm{C}^{14}$ destes depósitos permitiu estabelecer a cronologia dos eventos tectônicos.

As relações entre estruturas rúpteis, depósitos quaternários e feições geomorfológicas permitiram elaborar um quadro evolutivo preliminar, relacionando tectonismo e sedimentação recente na área de estudo.

\section{ESTRUTURAS RÚPTEIS E FEIÇÕES MORFOTECTÔ- NICAS ASSOCIADAS A análise de lineamentos} morfoestruturais indicou a presença das seguintes direções principais: NE-SW, ENE-WSW, N-S e NW-SE. As direções NE-SW e ENEWSW coincidem com a estruturação pré-cambriana, representada pelas foliações metamórficas das rochas (xistosidade e bandamento) e pelas zonas de cisalhamento de Jundiuvira, Paiol Grande e Buquira. As direções N-S e NW-SE têm sua origem possivelmente relacionada à uma estruturação mais recente. Os limites da borda do planalto acompanham as direções dos principais lineamentos de direções NE-SW, ENE-WSW e NW-SE.

As falhas recentes desenvolveram-se por reativação tectônica ao longo das zonas de fraqueza preexistentes. Os planos de falha são comumente revestidos por uma película fina, estriada, de óxidos e hidróxidos de manganês, sugerindo a idade recente dos falhamentos.

Três tipos principais de estruturas rúpteis foram identificadas no planalto. O primeiro tipo é representado por falhas de arranjo aproximadamente ortogonal (Fig. 2a), com direções ENE-WSW/WNW-ESE e NNW-SSE, mergulhos subverticais e rejeitos centimétricos a decimétricos, mostrando componentes direcionais dextrais e sinistrais, respectivamente, além de componentes normais. Tal disposição implica $\mathrm{cm}$ um regime de esforços com $\sigma_{1}$ situado a NW. Dado o caráter subvertical das falhas e a presença de deslocamentos de componente horizontal predominante, o regime tectônico vigente exigiria $\sigma_{2}$ na posição vertical, o que lhe confere provável caráter transcorrente. Essas falhas, que estão expressas no relevo pela presença de cristas e escarpas truncadas, shutter ridges, divisores pouco nítidos, capturas de drenagem e pelo condicionamento tectônico de trechos da drenagem conseqüente do planalto; ocorrem afetando stone-lines.

O segundo tipo é constituído por falhas normais de direção N-S e NE-SW/ENE-WSW, em parte paralelas à Zona de Cisalhamento de Jundiuvira, com mergulhos elevados e rejeitos centimétricos a decimétricos, que afetam stone-lines e horizontes A superficiais (Figs. $2 \mathrm{~b}$ e $2 \mathrm{c}$ ). Estas falhas ocorrem de modo generalizado no planalto, provocando capturas fluviais, vales assimétricos com escarpas retilíneas, facetas triangulares e trapezoidais e anfiteatros suspensos.

O terceiro tipo de estrutura corresponde a juntas de cisalhamento neotectônicas (no sentido de Hancock \& Engelder 1989), caracterizadas por mergulhos subverticais e espaçamento decimétrico a métrico; estas juntas seccionam os mais recentes colúvios, inclusive o horizonte superficial (A). O sistema de juntas da área estudada é caracterizado por fraturas conjugadas subverticais, que determinam ângulos diedrais inferiores a $45^{\circ}(\sigma$, horizontal situado na bissetriz do ângulo agudo). Entretanto, a estrutura em blocos subangulares ou prismática dos solos de Campos do Jordão (Comissão de Solos 1960) pode ser confundida com as juntas neotectônicas. Para diferenciar em campo estas duas estruturas foram adotados alguns critérios. Nas seções estudadas, as juntas neotectônicas têm caráter penetrativo mais pronunciado, grande continuidade lateral e, principalmente, evidenciam a persistên-
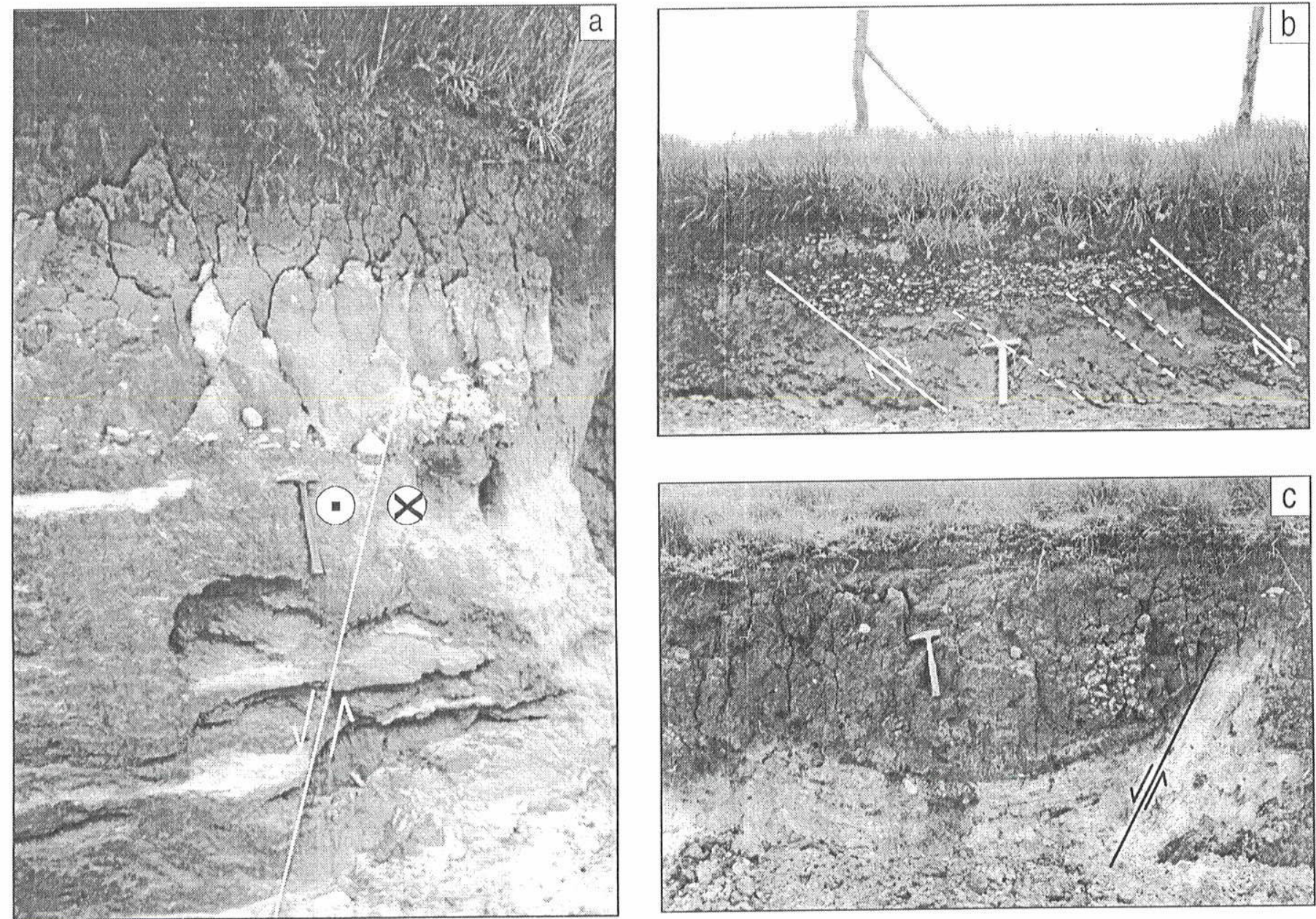

Figura 2: (a) falha transcorrente de diresão NNW com componente normal. Rejeito vertical de aproximadamente 20 cm, deslocando stone-lines do Pleistoceno Terminal; (b) falhas normais de reativacão, paralelas à foliaşão metamórfica (em tracejado), seccionando stone-lines do Pleistoceno Terminal; (c) depósito conglomerático estratificado preenchendo graben associado à falha normal de reativasäo. de diresão NE-SW, que desloca colúvios holocênicos. 
cia das direções e mergulhos. Estes últimos, bem expressos nos estereogramas, constituem argumento em favor da origem tectônica dessas estruturas. Em alguns perfis foi possível observar a continuidade das juntas até o embasamento pré-cambriano.

As estruturas rúpteis identificadas no planalto provocaram o surgimento de feições morfotectônicas, de grande expressão no relevo e na rede de drenagem. Falhamentos normais e transcorrentes são responsáveis por capturas de drenagem. Nos campos de São Francisco, Modenesi-Gauttieri et al. (1997, 2002) identificam capturas de drenagem nas cabeceiras do Ribeirão do Sino e do Córrego da Lavrinha, ao longo da Zona de Cisalhamento de Jundiuvira. Indícios de capturas são também observados nos campos do Jordão, ao longo dos córregos da Galhada, Campo do Meio e Ganha-Bola (Fig. 3), e no geossistema serrano. Nos campos de São Francisco, prováveis shutter ridges interrompem o curso do Ribeirão Galvão, subdividindo-o em três setores distintos que teriam evoluido de forma diferenciada (ModenesiGauttieri et al. 1997, 2002). Nos setores de cabeceira dos ribeirões Galvão e Grande, o arranjo de pequenas bacias de forma romboédrica, delimitadas por escarpas e facetas triangulares, que acompanham lineamentos de direções NW-SE e NE-SW, sugere uma origem semelhante à de bacias do tipo pull-apart. Os lagos do setor final do Ribeirão Galvão teriam sido originados por basculamentos tectônicos.

O caráter assimétrico do relevo é acentuado pelas escarpas retilíneas de direção NE-SW/ENE-WSW, que se desenvolvem ao longo da drenagem subseqüente do planalto. A amplitude das escarpas rochosas e abruptas voltadas para sudeste (Fig. 4a) varia de 20 a $70 \mathrm{~m}$ nos campos de São Francisco; no geossistema serrano pode atingir 150 - $200 \mathrm{~m}$. Em alguns casos, a amplitude das escarpas parece corresponder ao somatório dos rejeitos centimétricos a decimétricos de falhas normais com planos subparalelos pouco espaçados, observados em escala de afloramento. Esse fato poderia evidenciar sucessivas reativações tectônicas.
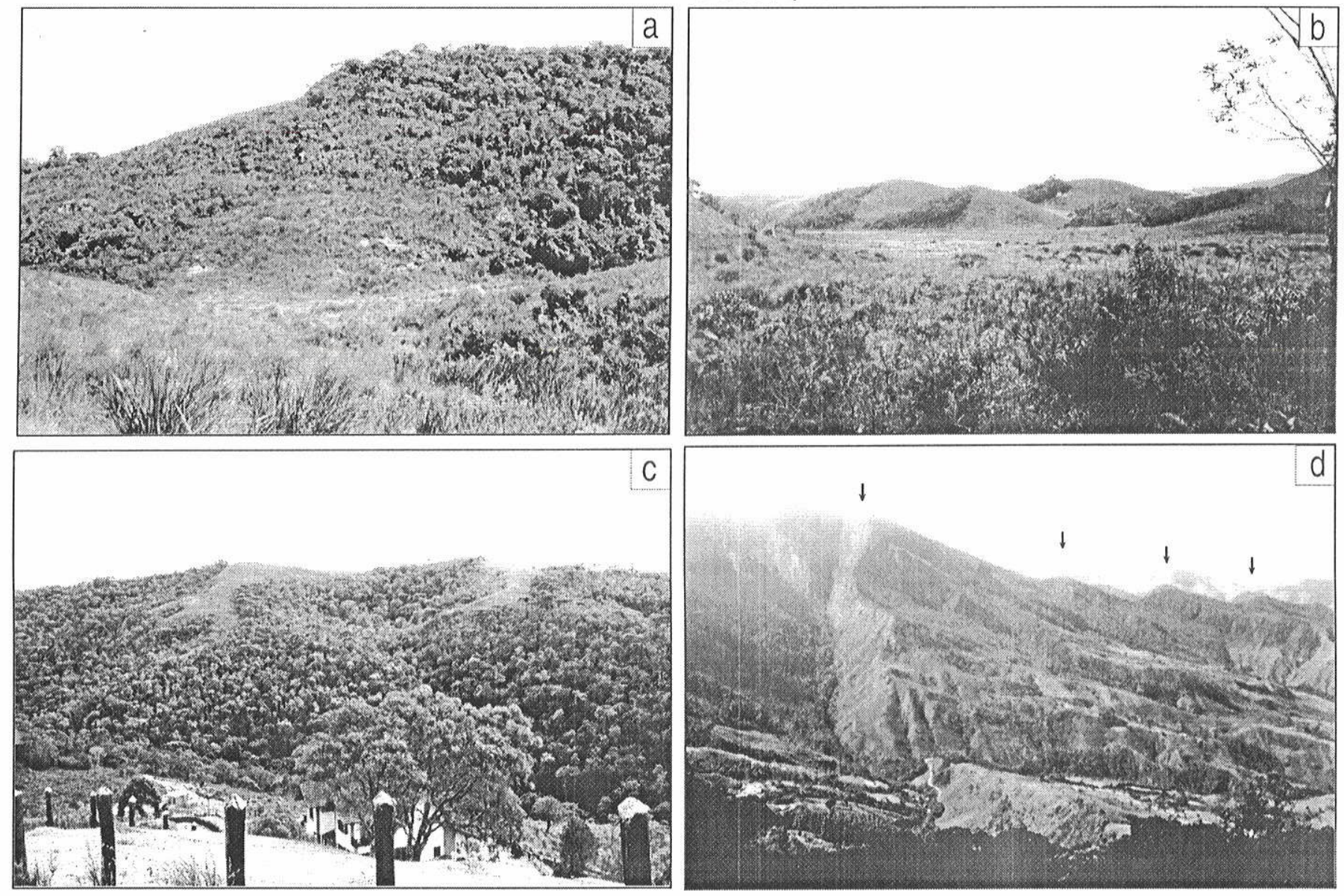

Figura 4: a) escarpas de direção NE-SW com vertentes abruptas e rochosas voltadas para sudeste; b) alinhamento de facetas triangulares segundo a diref̧ão NE-SW, associado a fallas normais; c) anfiteatro de erosão suspenso; d) sequiência de cristas assimétricas de dirę̧ão NE-SW, com vertentes abruptas voltadas para noroeste, associada a falhas normais (base da escarpa da Serra da Mantiqueira). 
1988b). Nos campos de São Francisco os anfiteatros ocorrem suspensos principalmente ao longo dos principais lineamentos e as rupturas de declive que os separam das várzeas atuais estão freqüentemente associadas a falhas com componente normal. Tais fatos sugerem a existência de um importante controle tectônico na geração dos anfiteatros.

A intersecção das falhas NE e NNW, frequentemente marcada nos campos de São Francisco por soleiras, divisores pouco marcados e prováveis shutter ridges, divide o planalto em blocos menores, corro- borando as idéias de Ruellan (1952) e Modenesi (1988a). Tais cruzamentos coincidem ainda com os profundos festões das cabeceiras dos rios Pirutinga e Taquaral na escarpa da Mantiqueira e com os sítios preferenciais para os fenômenos de captura de drenagem observados ao longo do divisor da Mantiqueira (Modenesi-Gauttieri et al. 2002).

$\mathrm{Na}$ base da escarpa da Serra da Mantiqueira, um perfil noroestesudeste mostra uma seqüência de cristas assimétricas com vertentes abruptas voltadas para noroeste (Fig. 4d), relacionada a falhas normais de direção ENE-WSW com mergulhos para NW.

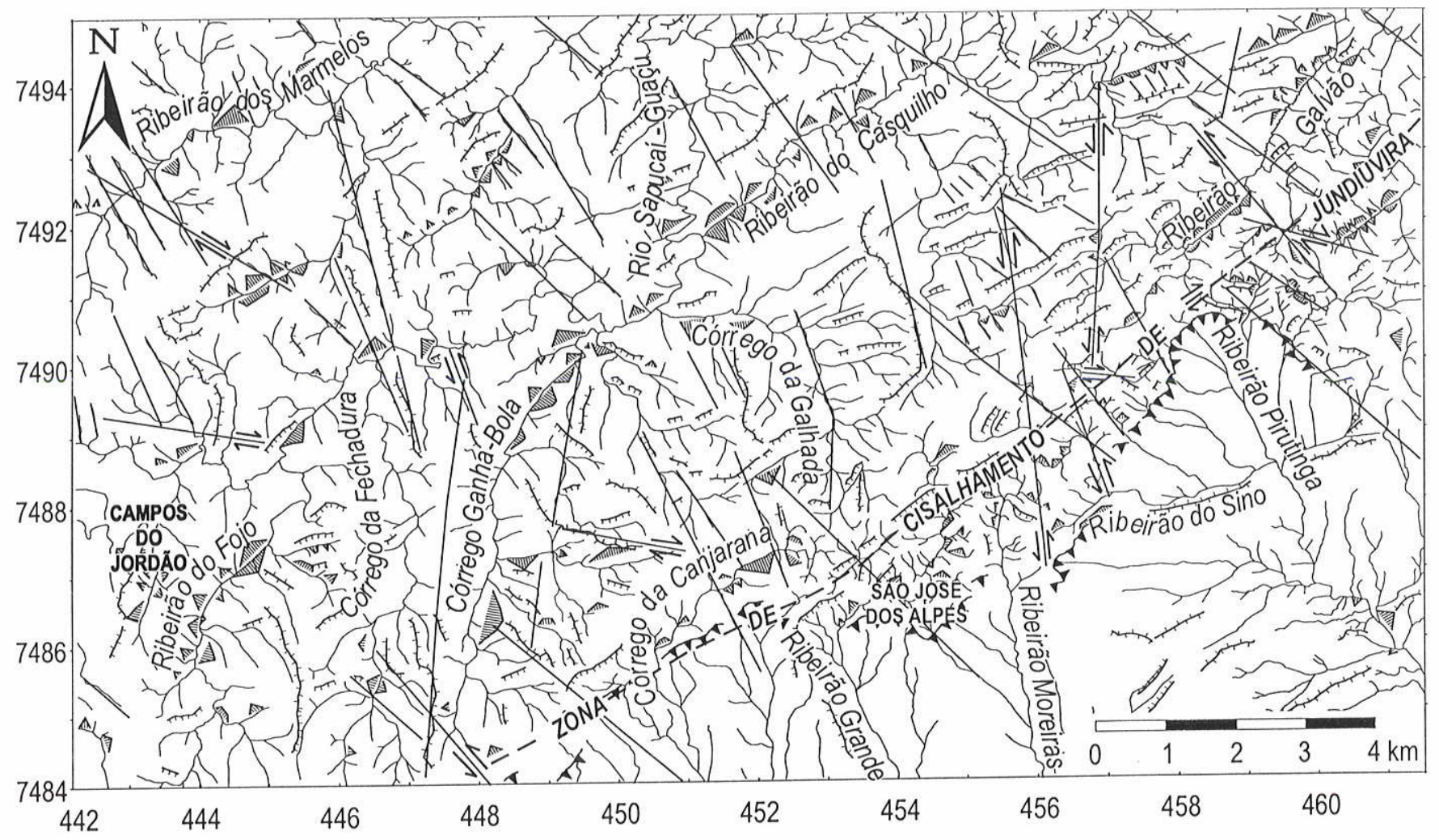

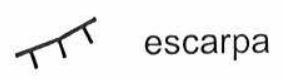

escarpa da Serra da Mantiqueira falha transcorrente

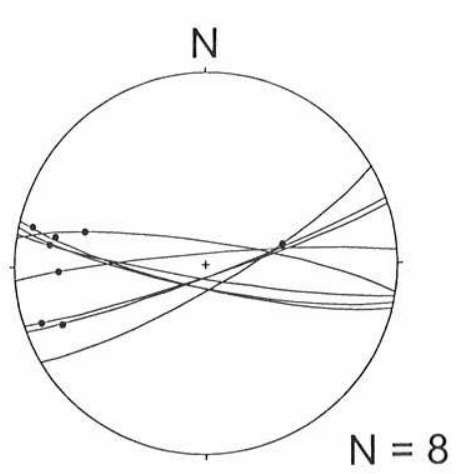

(a)

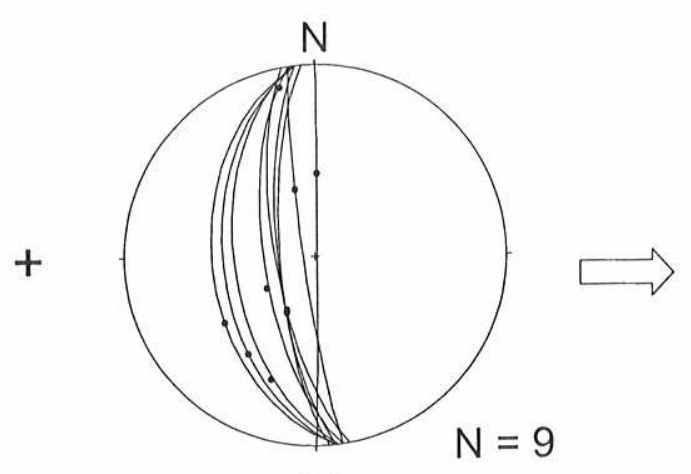

(b)

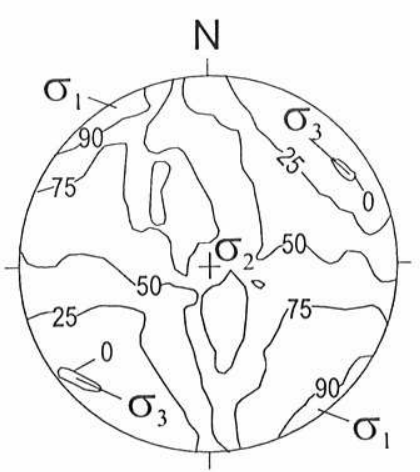

(c) Figura 5: Principais falhas relacionadas ao regime de esforģos compressivo de direção NW-SE associado ao binário transcorrente dextral E-W (Pleistocenol
Holoceno) e respectivos estereogramas (Rede de Schmidt - Lambert, hemisfério inferior de referência): (a) falhas transcorrentes (circulos máximos) de direç̃es ENE-WSW/WNW-ESE e caráter dextral com respectivas estrias (pontos); (b) fallhas transcorrentes (círculos máximos) de direção NNW-SSE e componente sinistral com respectivas estrias (pontos); (c) Dados tratados pelo método gráfico de Angelier \& Mechler (I977), utilizando o programa TRADE (Campanha et al. 1996). Isolinhas de porcentagem mais elevada delimitam campos de maior probabilidade de conter o eixo de tensão máximo, $\sigma_{l}$, e as de menor valor; o eixo de tensão mínimo, $\sigma_{3}$. 
EVOLUÇÃO DO REGIME DE ESFORÇOS DURANTE O QUATERNÁRIO Em trabalhos de neotectônica o balanço entre tectônica e sedimentação é estabelecido a partir de relações estratigráfico-estruturais. A aplicação desses métodos no Planalto de Campos do Jordão foi dificultada pelo fato dos depósitos quaternários serem descontínuos e pouco espessos, e também pela presença de poucos afloramentos com boas exposições de depósitos quaternários afetados por estruturas rúpteis.

Foram reconhecidos três regimes neotectônicos superpostos. Falhas transcorrentes de direções NNW - SSE e ENE - WSW/ WNW-ESE com componentes sinistrais e dextrais respectivamente, que cortam stone-lines, são compatíveis com um binário transcorrente dextral de direção E - W, com regime compressivo NW - SE, semelhante àquele observado no Rift Continental do Sudeste do Brasil (Riccomini 1989) de idade neopleistocênica a holocênica (Fig. 5). No rift, tais falhas afetam depósitos paleogênicos, stone-lines e condicionam altos estruturais (Arujá, Queluz, Floriano-Barra Mansa, Caçapava e Resende). Um segundo regime, distensivo E - W a NW - SE, é evidenciado pe-

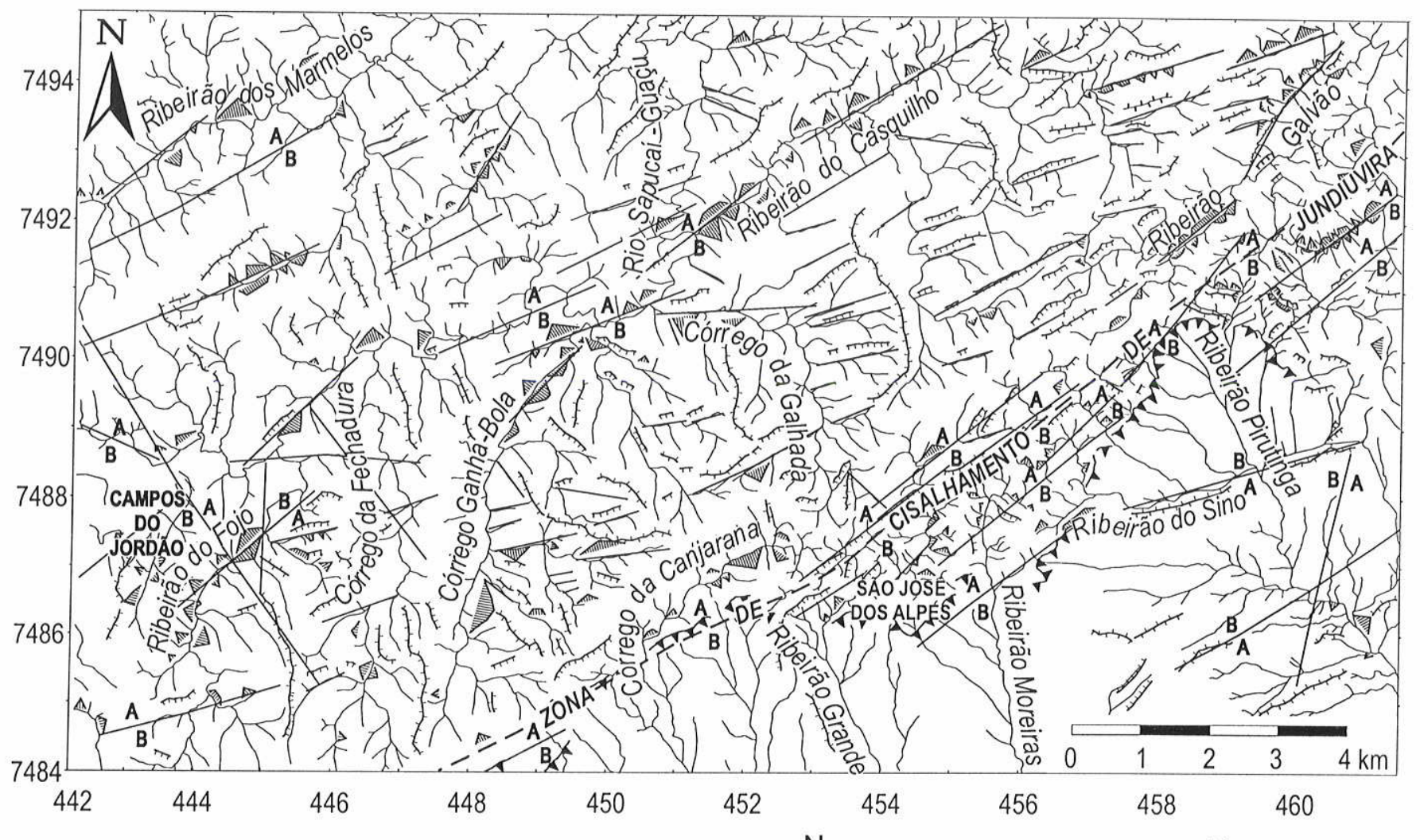

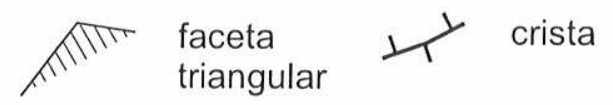

$\pi \begin{aligned} & \text { faceta } \\ & \text { trapezoidal }\end{aligned}$
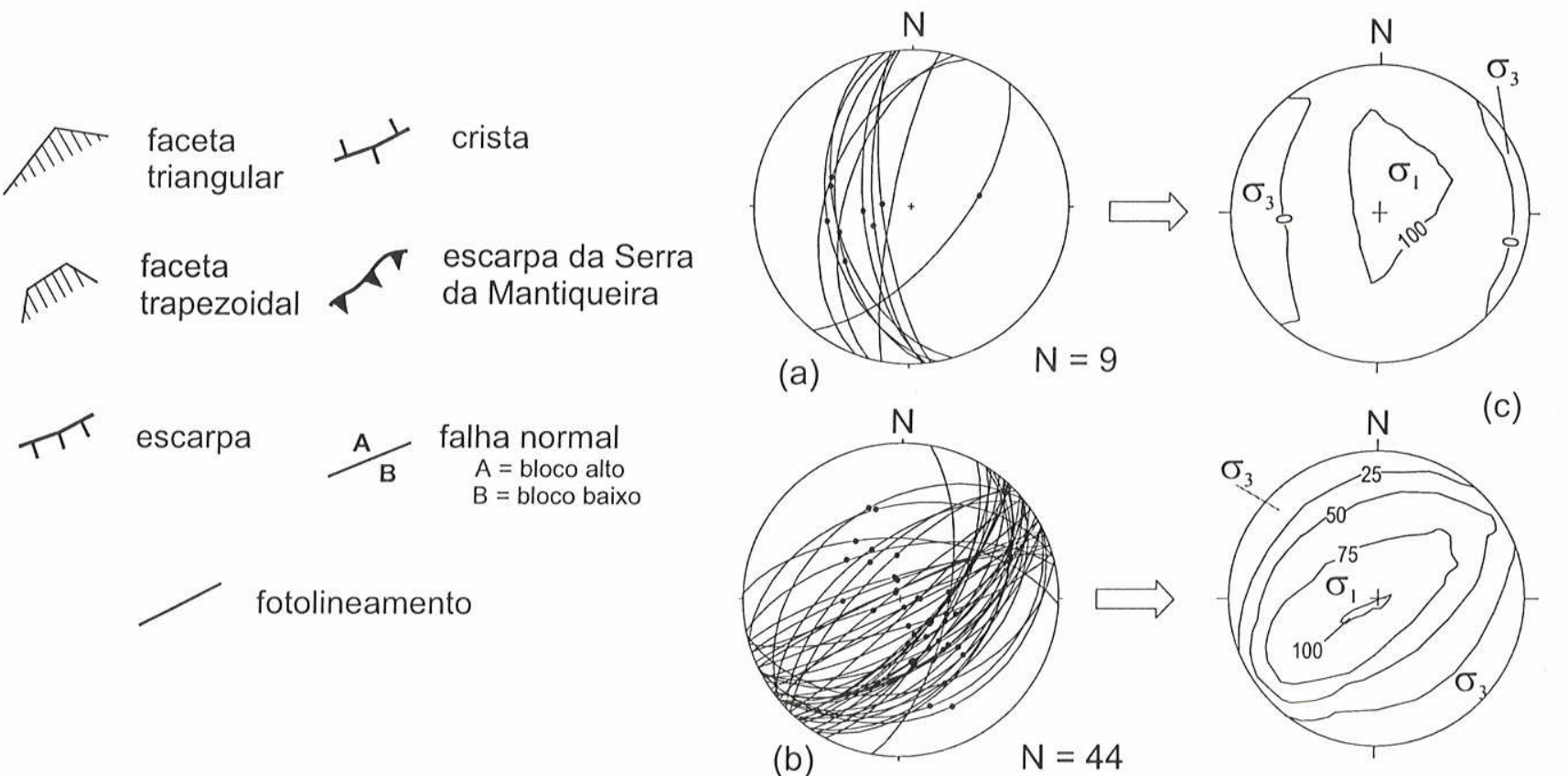

Figura 6: Principais falhas reativadas relacionadas ao regime distensivo NW-SE/E-W (Holoceno) e respectivos estereogramas (Rede de Schmidt-Lambert, hemisfério inferior de referência): (a) falhas normais (círculos máximos) de diresäo N-S com respectivas estrias (pontos); (b) fallas normais (círculos máximos) de diref̧ão NE-SW com respectivas estrias (pontos); (c) dados tratados pelo método gráfico de Angelier \& Mechler (1977), utilizando o programa TRADE (Campanha et al. 1996). Isolinhas de porcentagem mais elevada delimitam campos de maior probabilidade de conter o eixo de tensão máxima, $\sigma_{1}, e$ as de menor valor; o eixo de tensão mínimo, $\sigma_{3}$. 


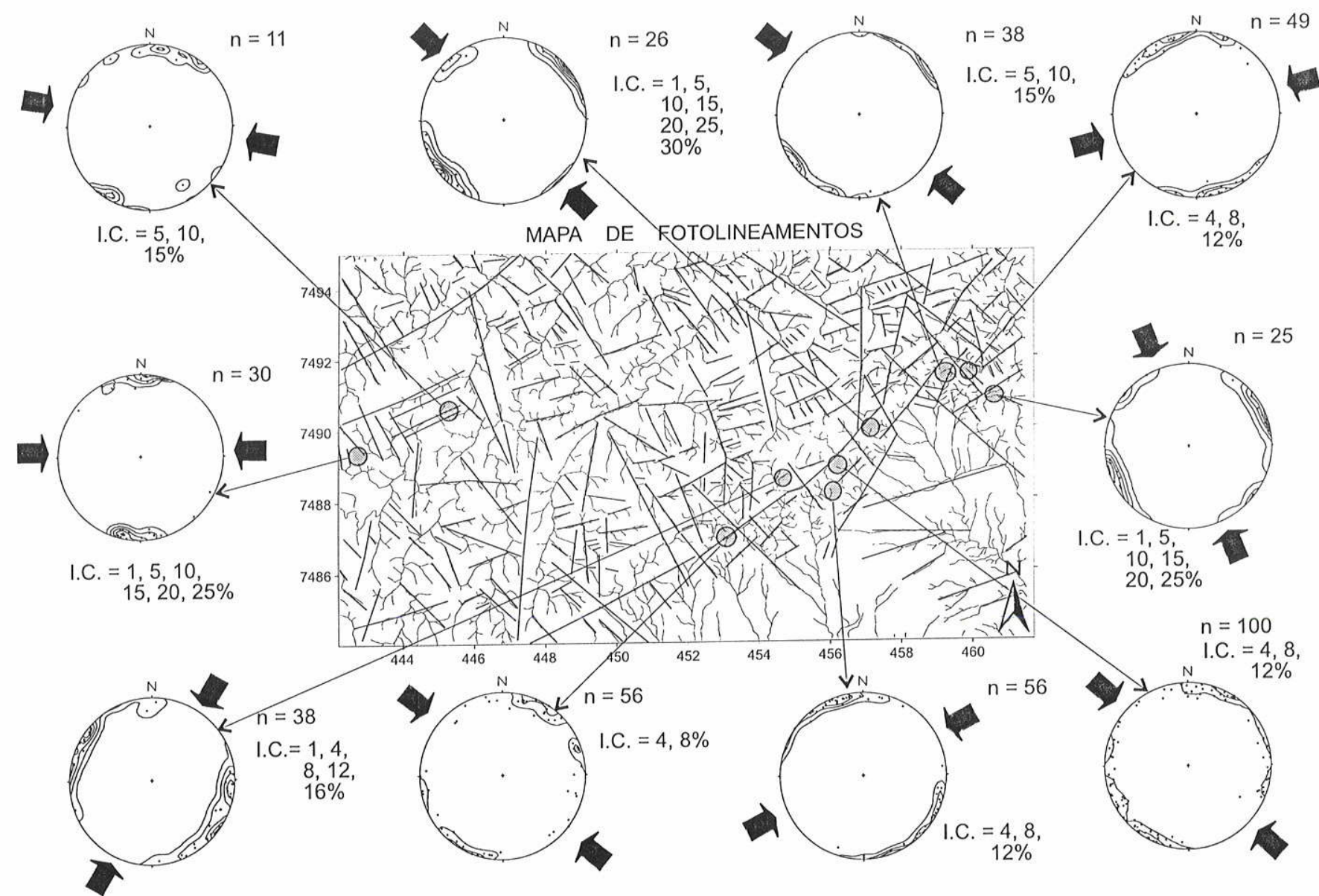

Figura 7: Regime de esforços compressivo de direção NW-SE a E-W estabelecido a partir de famílias de juntas conjugadas que afetam colúvios (CIII) e horizontes A superficial, em diversos setores da área de estudo. Pólos de juntas plotados em diagrama de Schumidt - Lambert, hemisfério inferior de referência; l.C. = intervalos de contorno das isolinhas, a partir do centro; setas indicam a direção do eixo $\sigma_{1}$.

las falhas normais de direção NE - SW (Fig. 6) que afetam horizontes húmicos superficiais datados em $9.250 \pm 170$ anos $\mathrm{AP}$ e $8.630 \pm 80$ anos AP (Hiruma 1999). Nestas duas primeiras fases, a Falha de Jundiuvira teria sido reativada inicialmente, por movimentação transcorrente dextral e, posteriormente, por falhas normais.

As estruturas mais recentes da área de estudo correspondem a juntas de cisalhamento subverticais que apresentam espaçamento decimétrico a métrico e persistência em suas orientações; afetam os colúvios mais recentes, inclusive o horizonte superficial (A). O arranjo do sistema de juntas sugere um regime final de esforços compressivo, de direção predominante E-W a NW-SE (Fig. 7). Este regime seria compatível com o regime atual de esforços horizontais máximos observado no sudeste do Brasil, a partir de dados geofísicos (Assumpção 1992).

A figura 8 ilustra uma primeira aproximação da relação entre sedimentação e tectônica no Planalto de Campos do Jordão. O caráter cíclico desta evolução, evidenciado por fases de maior ou menor atividade morfodinâmica nas vertentes, pode tanto ser explicado por desequilíbrio das condições climáticas como também por sucessivas reativações tectônicas (Modenesi-Gauttieri et al. 2002).

CONSIDERAÇÕES FINAIS O presente trabalho corrobora hipóteses levantadas em trabalhos anteriores sobre a presença de um tectonismo recente no Planalto de Campos do Jordão. As feições morfotectônicas mapeadas no frontão sudeste do planalto ocorrem diretamente associadas a falhamentos recentes. O mapeamento de feições morfotectônicas mostra-se uma importante ferramenta para subsidiar a análise neotectônica, principalmente em áreas pré-cambrianas com poucos registros sedimentares preservados, como o Planalto de Campos do Jordão. Anfiteatros suspensos, facetas triangulares c trapezoidais, vales assimétricos e escarpas retilíneas associam-se

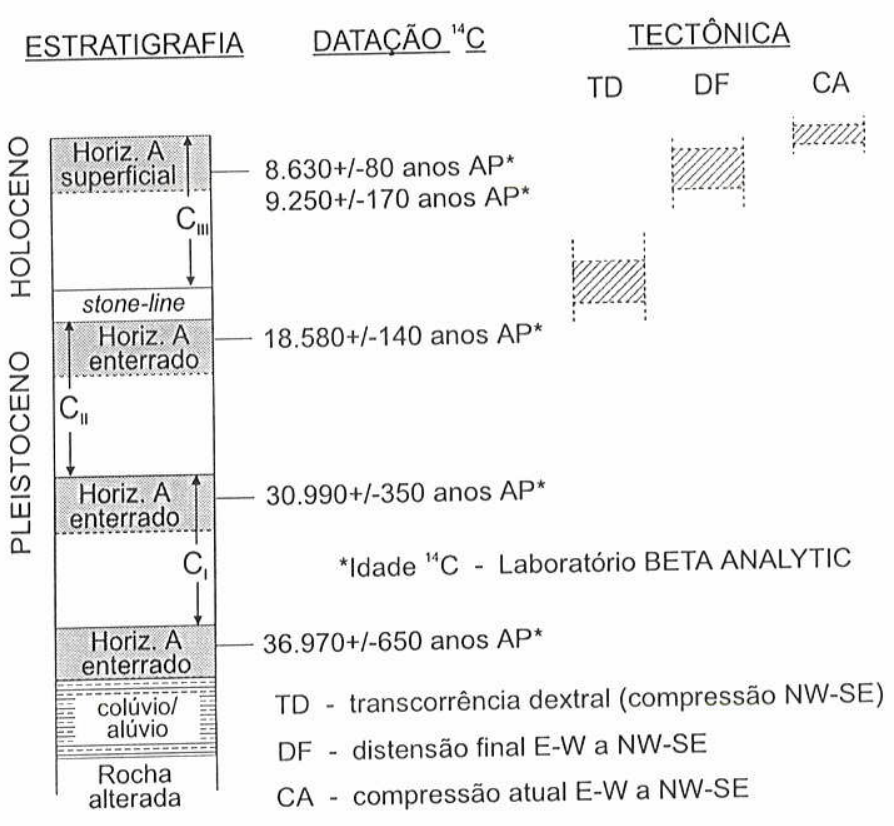

Figura 8: Quadro preliminar da relação entre sedimentação quaternária e tectônica no Planalto de Campos do Jordão. Representação esquemática da estratigrafia do Quaternário baseada em Modenesi (1988a). 
freqüentemente a falhas com componente normal; cristas truncadas, divisores pouco nítidos e shutter ridges refletem falhas com componente transcorrente. Capturas de drenagem e rios em gancho ocorrem associados aos dois tipos de falhas.

As falhas observadas resultam da reativação tectônica em zonas de fraqueza pré-cambrianas, como a que existe ao longo da Zona de Cisalhamento de Jundiuvira. Este fato vem destacar a importância da estruturação regional antiga na evolução do quadro neotectônico c corrobora as idéias sobre "tectônica ressurgente" (Hasui \& Ponçano 1978, Hasui 1990).

Os três regimes neotectônicos superpostos identificados no Planalto de Campos do Jordão (compressão NW - SE, distensão E-W a NWSE e compressão E-W/NW-SE) evidenciam a continuidade (orientação e idade) dos regimes de esforços identificados em áreas vizinhas, como o Vale do Rio Paraíba do Sul e a região do Alto de Queluz, e mais distantes, como o Médio Vale do Rio Doce.

Verifica-se que as variações nos campos de esforços durante o Neopleistoceno e Holoceno foram muito rápidas. Entretanto, é provável que o evento distensivo corresponda a uma fase de relaxamento superficial de esforços, com falhas normais, dentro de um regime regional compressivo (Riccomini et al. 1989, Salvador \& Riccomini 1995, Mello 1997, Riccomini \& Assumpção 1999).

Agradecimentos À Fundação de Amparo à Pesquisa do Estado de São Paulo - FAPESP (Processo 96/08239-5), pelo auxílio financeiro que permitiu a realização deste trabalho.

\section{Referências}

Ab'Sáber A.N. 1956. A terra paulista. Boletim Paulista de Geografiäa, São Paulo, 23: 5-38. Ab'Sáber A.N. \& Bernardes N. 1958. Vale do Paraíba, Serra da Mantiqueira e arredores de Sāo Paulo. In: CNG, Congr. Intern. Geogr., 18, Rio de Janeiro, Guia de Excursĩeses, 4: $304 \mathrm{p}$.

Almeida F.F.M. 1964. Fundamentos geológicos do relevo paulista. Boletim do Instituto Geográfico e Geológico, 41:169-263.

Almeida F.F.M. 1967. Origem e evolução da Plataforma Brasileira. Rio de Janeiro, DNPM/DGM, 36 p. (Boletim 241).

Almeida F.F.M. 1976. The system of continental rifts bordering the Santos Basin, Brazil. Anais da Academia Brasileira de Ciências, 48 (Suplem.):15-26.

Almeida F.F.M., Hasui Y., Brito Neves B.B. 1976. The upper Precambrian of South America. São Paulo, Instituto de Geociências - USP, 5-80 (Boletim 7).

Amaral G., Born H., Hadler N. J.C., Iunes P.J., Kawashita K., Machado JR. D.L., Oliveira E.P., Paulo S.R., Tello S. C.A. 1997. Fission track analysis of apatites from São Francisco craton and Mesozoic alcaline-carbonatite complexes from central and southeastern Brazil. Journal of South American Earth Sciences, 10(3/4): 285-294.

Angelier J. 1976. La néotectonique cassante et sa place dans un are insulaire: l'arc égéen méridional. Revue de Geologie Dynamique et de Geographie Physique, 18:1257. 1265.

Angelier J. 1994. Fault slip analysis and palaeostress reconstruction. In: P.L. Hancock (ed.) Continental Deformation. I" ed., Oxford, Pergamon Press, 53-100.

Angelier J. \& Mechler P. 1977. Sur une méthode graphique de recherche des constraintes principales également utilisable en tectonique et en séismologie: la méthode des dièdres droits. Bulletin de la Société Géologique de France, 7 : 1309-1318.

Asmus H.E. \& Ferrari A.L. 1978. Hipótese sobre a causa do tectonismo cenozóico na região sudeste do Brasil. In: Aspectos estruturais da margem continental leste e sudeste do Brasil, Rio de Janeiro, CENPES/DINTEP, p. 75-88 (Série Projeto REMAC 4).

Assumpção M. 1992. The regional intraplate stress field in South America. Journal of Geophysical Research, 97(B8):11889-11903

Biancotti A. 1979. Rapporti fra morfologia e tettonica nella pianura cuneese. Geografia Fisicia e Dinamica Quaternaria, 2: 51-56.

Campanha G.A.C., Carneiro C.D.R., Pereira Júnior G.G., Furumoto S., Hasui Y., Nagata N. 1996. Uso do programa Trade para determinação de direções principais de esforços pelos métodos Arthaude Angelier. In: C.D.R. Carneiro (ed.) Projescão estereogrcáfica para análise de estruturas. São Paulo, UNICAMP/CPRM/IPT, 116-120.

Cavalcante J.C., Cunha H.C.S., Chieregati L.A., Kaefer L.Q., Rocha J.M., Daitx E.C., Coutinho M.G.N., Yamamoto K., Drumond J.B.V., Rosa D.B., Ramalho R. 1979. Projeto Sapucai - Estados de Minas Gerais e São Paulo. Relatório Final de Geologia. Brasília, DNPM/CPRM, 299 p. (Série Geologia 5, Seção Geologia Básica 2).

Comissão de Solos. 1960. Levantamento de reconhecimento dos solos do Estado de São Paulo. Rio de Janeiro, Ministério da Agricultura, Serviço Nacional de Pesquisas Agronômicas, 634 p. (Boletim 12).

Cotton C.A. 1948. Landscape - as developed by the processes of normal erosion. 2 ed., New York, John Wiley \& Sons, 509 p.

De Martonne E. 1943. Problemas morfológicos do Brasil tropical Atlântico. Revista Brasileira de Geografia, 4: 523-550.

Doblas M., Mahecha V., Hoyos M., López-Ruiz J. 1997. Slickenside and fault surface kinematic indicators on active normal faults of the Alpine Betic cordilleras, Granada, southern Spain. Journal of Structural Geolog!; 19(2): 159-170.

Doornkamp J.C. 1986. Geomorphological approaches to the study of neotectonics. Journal of the Geological Society, 143: 335-342.

Freitas R.O. 1951. Ensaio sobre a tectônica moderna do Brasil. São Paulo, FFCL - USP, 120 p. (Boletim 130 Geologia 6).

Gallagher K., Hawkesworth C.J., Mantovani M.S.M. 1995. Denudation, fission track analysis and the long - term evolution of passive margin topography: application to the southeast Brazilian margin. Journal of South American Earth Sciences, 8(1): 6577

Gontijo A.H.F. 1999. Morfotectônica do Médio Vale do Rio Paraíba do Sul: região da Serra da Bocaina, leste do Estado de São Paulo. Instituto de Geociências e Ciências Exatas, UNESP, Rio Claro, Tese de Doutoramento, $265 \mathrm{p}$.

Hackspacher P., Hadler N. J.C., Iunes P.J., Paulo S.R., Ribeiro L.F.B., Tello S. C.A. 1999. Alguns dados sobre o Período Cretáceo na Serra da Mantiqueira através de análise de traços de fissão em apatitas (ATFA). In: UNESP, Simpósio sobre o Cretáceo do Brasil, 5, Serra Negra, Boletim, 33-37.

Hancock P.L. \& Engelder T. 1989. Neotectonic joints. Geological Society of America Bulletin, 101:1197-1208.

Hasui Y. 1990. Neotectônica e aspectos fundamentais da tectônica ressurgente no Brasil. In: SBG, Workshop sobre Neotectônica e Sedimentação Cenozóica Continental no Sudeste Brasileiro, I, Belo Horizonte, Bol. Soc. Bras: Geol. - Núcleo Minas Gerais, 11: $1-31$.

Hasui Y. \& Mioto J.A. 1992. Geologia estrutural aplicada. São Paulo, ABGE/ VOTORANTIM, $459 p$.

Hasui Y. \& Ponçano W.L. 1978. Geossuturas e sismicidade no Brasil. In: ABGE, Congr: Bras. Geol. Eng., 2, São Paulo, Anais, 1:331-338.

Hasui Y., Facincani E.M., Santos M., Jiménez-Rueda J.R. 1995. Aspectos estruturais e neotectônicos na formação de boçorocas na região de São Pedro, SP. Geociênciass, 14(2): 59-76.

Hasui Y.. Ponçano W.L., Bistrichi C.A., Stein D.P., Galvão C.A.C.F., Gimenez A.F., Almeida M.A., Pires Neto A.G., Melo M.S., Santos M.C.S.R. 1978. Geologia da Região Administrativa 3 (Vale do Paraíba) e parte da Região Administrativa 2 ( Litoral) dos Estado de São Paulo. Instituto de Pesquisas Tecnológicas, São Paulo, 78 p. (Publicação 1106).

Hiruma S.T. 1999. Neotectônica no Planalto de Campos do Jordão, SP. Instituto de Geociências, USP, São Paulo, Dissertação de Mestrado, 106 p.

Liu C.C. 1987. A geologia estrutural do Estado do Rio de Janeiro vista através de imagens MSS do Landsat. In: SBG, Simpósio de Geologia Regional RJ-ES, 1, Rio de Janeiro, Anais, $164-188$.

Mancini F. 1995. Estratigrafia e aspectos da tectônica deformadora da Formação Pindamonhangaba, Bacia de Taubaté, SP. Instituto de Geociências, USP, São Paulo, Dissertação de Mestrado, $107 \mathrm{p}$.

Mello C.L. 1997. Sedimentą̧ão e tectônica cenozóicas no Médio Vale do Rio Doce (MG. Sudeste do Brasil) e suas implicações na evolução de um sistema de lagos. Instituto de Geociências, USP, São Paulo, Tese de Doutoramento, 275 p.

Mello C.L., Moura J.R.S., Carmo I.O., Silva T.M., Peixoto M.N.O. 1995. Eventos de sedimentação durante o Holoceno no Médio Vale do Rio Paraíba do Sul (SP/RJ) aloestratigratia e datações por radiocarbono. In: ABEQUA, Congr. Assoc. Bras. Est. Quat., 5, Niterói, Anais, 193-200.

Mioto J.A. 1993. Sismicidade e zonas sismogênicas do Brasil. Instituto de Geociências e Ciências Exatas, UNESP, Rio Claro, Tese de Doutoramento, vol. 1, 276 p.

Modenesi M.C. 1980. Intemperismo e morfogênese no Planalto de Campos do Jordão, São Paulo. Revista Brasileira de Geociências, 10(3):213-225.

Modenesi M.C. 1983. Weathering and morphogenesis in a tropical plateau. Catena, 10(3):237-25I.

Modenesi M.C. 1984. Evolução quaternária de uma montanha tropical: o Planalto de Campos do Jordão, São Paulo. Revista do Instituto Geológico, 5(1/2):7-13.

Modenesi M.C. 1988a. Significado dos depósitos correlativos quaternários em Campos do Jordão - São Paulo: implicą̧ões paleoclimáticas e paleosecológicas. São Paulo, Instituto Geológico, 155 p. (Boletim 7).

Modenesi M.C. 1988b. Quaternary mass movements in a tropical plateau (Campos do Jordão, São Paulo, Brazil). Zeitschrift fiir Geomorphologie, 32(4):425-440. 
Modenesi-Gauttieri M.C., Hiruma S.T., Riccomini C. 1997. Morfotectônica dos altos Campos de São Francisco (Planalto de Campos do Jordão - SP). In: SBG/ABGE, Simpósio de Geologia do Sudeste, 5, Penedo, Atas, 77-79.

Modenesi-Gauttieri M.C., Hiruma S.T., Riccomini C. 2002. Morphotectonics of a high plateau on the northwestern flank of the Continental Rift of Southeastern Brazil. Geomorphology: 43(3/4):257-271.

Morais S.M. 1998. Carta geológica - Folha Guaratinguetá (SF.23-Y-B), escala 1:250.000 São Paulo, CPRM - Superintendência Regional de São Paulo, Programa Levantamentos Geológicos Básicos do Brasil.

Mörner N. 1989. Introduction. In: Mörner \& Adams (ed.), Special Issue: Paleoseismicity and Neotectonics, Tectonophysics, 163(3/4): 181-184.

Mörner N. 1993. Neotectonics, the new global tectonic regime during the last $3 \mathrm{Ma}$ and the initiation of Ice Ages. Anais da Academia Brasileira de Ciências, 65(Supl. 2): 295 -301 .

Obruchev V.A. 1948. Osnovnye cherty kinetiki i plastiki neotektoniki. Akademia Nauk SSSR, Izveztịa Serịa Geologiya, 5:13-24.

Panizza M. \& Castaldini D. 1987. Neotectonic research in applied geomorphological studies. Zeitschrift fiir Geomorphologie, Suplem. 63 (Neotectonics and morphotectonics): 173 - 211 .

Pavlides S.B. 1989. Looking for a definition of neotectonics. Terranov'a, 1(3): 233-235.

Petit J.P. 1987. Criteria for the sense of movement on fault surfaces in brittle rocks. Journal of Structural Geology: 9(5/6): 597-608.

Riccomini C. 1989. O rift continental do sudeste do Brasil. Instituto de Geociências, USP, São Paulo, Tese de Doutoramento, $256 \mathrm{p}$.

Riccomini C. 1993. Origem, evolução e inversão da Bacia do Pico de Itapeva, Neoproterozóico - Cambriano, São Paulo, Brasil. In: Dinamige - Facultad de Agronomia, Simposio Internacional del Neoproterozoico - Cambrico de la Cuenca del Plata, I, La Paloma - Minas (Uruguai), Resumenes Extensos, 1(16), s/p.

Riccomini C. 1997. Arcabouço estrutural e aspectos do tectonismo gerador e deformador da Bacia Bauru no Estado de São Paulo. Revista Brasileira de Geociências, 27(2): 153 162.

Riccomini C. \& Assumpção M. 1999. Quaternary tectonics in Brazil. Episodes, 22(3): 221225.

Riccomini C. \& Crósta A.P. 1988. Análise preliminar de lineamentos em imagens de sensores remotos aplicada à prospeç̧ão mineral na área dos granitóides Mandira, SP. São Paulo, Instituto de Geociências-USP, p. 23-37 (Boletim 19, Série Científica).
Riccomini C., Peloggia A.U.G., Saloni J.C.L., Kohnke M.W., Figueira R.M. 1989. Neotectonic activity in the Serra do Mar rift system (southeastern Brazil). Journal of South American Earth Sciences, 2(2): 191-197.

Ruellan F. 1952. Excursão à região do Vale do Paraíba e à Serra da Mantiqueira. In: Reunião Panamericana Consulta sobre Geogr., 1, Guia de excursão B. I., set./1949, Ancuis, 2: 206-251.

Saadi A. 1991. Ensaio sobre a morfotectônica de Minas Gerais: tensões intra-placa, descontinuidades crustais e morfogênese. Instituto de Geociências, UFMG, Belo Horizonte, Tese para cargo de Professor Titular, $285 \mathrm{p}$.

Saadi A. 1993. Neotectônica da plataforma brasileira: esboço e interpretação preliminares. Geonomos, 1(1): 1-15

Salvador E.D. \& Riccomini C. 1995. Neotectônica da região do Alto Estrutural de Queluz (SP-RJ, Brasil). Revista Brasileira de Geociências, 25(3): 151-164.

Santos M. Hasui Y., Morales N., Borges M.S., Garcia M.J. 1999. Evolução cenozóica da região de Aiuruoca, sul de Minas Gerais. In: SBG/UNESP, Simpósio de Geologia do Sudeste, 6, São Pedro, Boletim de Resumos, 81.

Schobbenhaus C., Campos D.A., Derze G.R., Asmus H.E. 1984. Geologia do Brasil. Texto explicativo do Mapa Geológico do Brasil e da área oceânica adjacente incluindo depósitos minerais - escala 1:2.500.000. Brasília, MME/DNPM, 501 p.

Silva C.G. \& Ferrari A.L. 1997. Neotectonismo no litoral nordeste do Estado do Rio de Janeiro. In: SBG, Simpósio de Geologia do Sudeste, 5. Penedo, Atas, 80-82

Stewart I.S. \& Hancock P.L. 1990. What is a fault scarp? Episodes, 13(4): 256-263.

Stewart I.S. \& Hancock P.L. 1994. Neotectonics. In: P.L.HANCOCK (ed.), Cominental deformation. Oxford, Pergamon, 370-409.

Vita-Finzi C. 1986. Recent Earth movements - an introduction to neotectonics. 2 ed. London, Academic Press, 226 p.

Wallace R.E. 1978. Geometry and rates of change of fault-generated range fronts, NorthCentral Nevada. Journal of Research of the U.S. Geological Survey, 6(5): 637-650.

Zalán P.V. 1986. A tectônica transcorrente na exploração de petróleo: uma revisão. Revista Brasileira de Geociências, 16(3):245-257.

Manuscrito A-1218

Recebido em 16 de março de 2001

Revisão dos autores em 28 de outubro de 2001

Revisão accita em 30 de outubro de 2001 